\title{
OCEANATLAS AND ATLAST
}

\author{
By Larry Atkinson
}

\begin{abstract}
Most of us spend a great deal of time looking at data, visualizing it in our mind, and interpreting it for others. I am sure we all have also often realized how much time we spend on the unproductive part of these tasks. How often have you said, "I could have done this faster by hand!" I looked at two free software packages, OceanAtlas (OA) and Atlast, with success, but I wondered what longtime users thought of them. OceanAtlas is for the Mac and Atlast for the PC. Both have extensive data visualization capability and both come with large datasets: thus the atlas component of the names. To start with I sent out an E-mail query to some OceanAtlas users. Since the comments I received were so good, this column will be a collection of their responses. Although most of these comments are about OceanAtlas they apply equally well in most cases to Atlast.
\end{abstract}

First some comments by Jim Swift (Scripps Institution of Oceanography), an originator of OceanAtlas, on what OceanAtlas is and a bit of its history.

“. . . my initial idea was to put all Joe's [Joseph Reid] software and all Joe's data onto a computer with an interactive display to search, plot, and explore the data on-screen . . . After John Osborne introduced me to the Macintosh in 1987 [and its capabilities] I submitted proposals to NSF and ONR to do this. [The proposals were not funded and] . . . the whole thing may have died except for Peter Rhines, who was showing an electronic data display program, 'Atlast,' he had written for IBM-PCs that worked well with section-oriented data. Oz [John Osborne, NOAA/PMEL] and I immediately started work on OceanAtlas for Macintosh when we saw Atlast. [Because of machine differences and new ideas] OceanAtlas took a separate path."
"I saw OceanAtlas as both an ad hoc electronic atlas of ocean sections and as a tool for examining new data sets, a true open-ended data exploration environment. I wanted it to have personality, and so chose the viewpoint of interpretative physical oceanography."

Now I'd like to quote from some research users of OA.

"I use OA to examine hydrographic and tracer data . . mainly for property:property plots and vertical sections. The property plots can display three parameters by using color to represent one parameter and the $\mathrm{x}$ and $\mathrm{y}$ coordinates to represent the other two. Parameters not stored, such as density or potential vorticity or any parameter you define that can be determined from stored parameters, can be readily calculated and plotted. The program is easy to use and fast. If you are interested in seeing if a particular feature is in a data set, it is just as quick to find it using $\mathrm{OA}$ as it is to look it up in a hard copy atlas of the data set, and you can display it in many ways. OA runs well on the newer Macintosh powerbooks making it easy to access and work with an enormous amount of data anywhere you go." [Bill Smethie, Lamont Doherty Earth Observatory]

"It was particularly valuable on a cruise last summer to the Denmark Strait region where I used it to compare our onboard T/S data with historical data sets." [Chris Measures, SOEST, University of Hawaii]

"You may be interested to learn that I used OA to produce TS-diagrams and Tzcurves for several illustrations in my new textbook "Regional Oceanography: an Introduction." [Matthias Tomczak, Flinders University]

"I have used OA at sea to provide the scientific party access to historical sec- tions at, or near, our study area. These sections can consist of whatever parameters are available in the OA historical files." [Don Atwood, NOAA/AOML]

Here are some comments from people using $\mathrm{OA}$ in the classroom.

"From a teaching perspective I think it's one of the best and most useful pieces of software written for chemical and physical oceanography. With a minimum of computer skills and an introductory knowledge of oceanography, students in my classes have learned to explore principles of water transport and marine chemistry that few textbooks even begin to approach. The range of options in selecting and plotting data is magnificent, and the 'hot link' feature of the data is especially useful. The more advanced features, such as flux and transport calculations, interpolations, and scripting are better suited to more sophisticated users, but cleanly illustrated and useful for 'show and tell' style presentations." [Carl Bowser, University of Wisconsin]

"I've found OA a very powerful tool and have given my physical oceanography class assignments using it. Because OA is somewhat unresponsive on anything less than a Quadra, I have written a MatLab program that does much of the dynamics and tracers. The two programs compliment each other well. One comment that a student made was that any of these programs take some time to learn so multiple assignments are effective." [Tom Rossby, University of Rhode Island]

"OA is great for displaying section data and surface plots of standard oceanographic parameters. We are compiling a digital atlas of historical Indian Ocean physical and biological observations and plan to provide OA as a display tool." [Mark Luther, University of South Florida] 
Our past president had a comment that reflects on data analysis.

"We all marvel at the skill of the pre-1960 oceanographers. They draw such sweeping conclusions based on so few data points. Subsequent studies often proved them correct and stamped their names on many key concepts of modern oceanography. We usually simply say they had lots of time to think about small data sets (plus many of them were really smart). Now a days we are swamped with observational and model data. It seemed for a while that we would drown in data. Except for the most computer literate of our community, we didn't have the tools to work with these data. User friendly computer software for the powerful computers now at our disposal was desperately needed to allow us to wade through these data. OA is one of the best user friendly quick-look tools we have. OA is one of the software packages that will really bring research and educational benefits to our science." [Arnold Gordon, Lamont Doherty Earth Observatory]

What are the problems with OA? The only ones mentioned were data ingestion and lack of publication quality graphics. Data can be ingested if one has some skills, and graphics can be imported to graphics packages for final touchups.

I asked John Osborne [NOAA/PMEL], the person who wrote $\mathrm{OA}$, about the relation between $\mathrm{OA}$ and commercial packages such as MatLab, IDL or Splus. His response was as follows: "The relation of $\mathrm{OA}$ to commercial packages question is a good one. I'm not expert with these products but I do know they are very capable but require a fair amount of computer savvy to utilize their potential. OA is really targeted toward the nonprogrammer oceanographer (there are many out there) and students. It does a small subset of what is theoretically available in the commercial packages but it does it well. It was written by and for oceanographers. The linked browsing feature of OA is where OA really shines. Also, OA makes using color as a third dimension very straight forward."

Now l'd like to give some comments from Peter Rhines, the developer of Atlast, the original ocean data visualization product.

"The whole idea of an atlas is to lure a much broader group into looking at the oceans. The teaching aspect is powerful. Yet, in addition, I have found that at sea, my Toshiba loaded with historic sections becomes a touch point as we look at the new hydrographic data coming up the wire. Combined with Matlab, the self-contained atlases make quite a research tool. As the large number of WOCE lines becomes public, and as Syd Levitus unearths more data with his 'archaeology' project, I think the need for organized software of this kind will be great. I have also found that, sitting in meetings, I can pull up data to answer a murky question under discussion, my computer nearly concealed on my lap.

"What is missing at this point is a textbook to accompany the software. I find that people looking over my shoulder learn quickly what to do, whereas the manual has not taught them (despite 'worked out examples' therein). Perhaps one of us will come through with a text soon. In the future of course there will be atlases with wider scope, full of drifters, current meters, satellite imagery as well as hydrography. But there needs to be a balance between technical capability and intellectual utilization; great to have these tools, but thinking and discovering has to keep up. We know that hardware is outrunning good software, but also software is outrunning thinking and use. Otherwise, our scientific life turns into a kind carnival; bright colors, loud music, lots of fun, but hardly a solver of great problems or generator of great insights."
John Osborne also mentioned that "OA might go commercial in the near future." He further stated that: "This will translate into a better, more stable application, more features (especially, properties interpolated onto horizontal (lat/lon) surfaces), technical support, a database engine to allow arbitrary sections to be constructed on the fly from OA datasets, a native Power Macintosh version, and perhaps professional and educational versions (cheaper, simpler). All at very reasonable prices (upgrades $<\$ 100$ and original copies < \$200). The commercial version of OA should smooth out data ingest and allow better integration with other tools."

Until I corresponded with John and Peter I felt that most people, given a choice, would use the commercial packages. However, now 1 realize that there are many users who will not program the commercial products and there is a real need for products like $\mathrm{OA}$ and Atlast.

A final quote from our President, Margaret Leinen.

"I like to use OA to 'play' with data on airplane flights. I make a mental hypothesis about some parameter relationship in some region and then test the hypothesis using OA."

To obtain OceanAtlas or Atlast send a request to:

User Services Office

JPL Physical Oceanography DAAC

Jet Propulsion Laboratory, MS 300-320

4800 Oak Grove Drive

Pasadena, CA 91109

Internet: podaac@podaac.jpl.nasa.gov

Omnet: PO.DAAC.JPL

Phone: 818-354-9890

Fax: 818-393-2718

Note: The next issue will feature OPCPLOT. After that we will review oceanographic CD-ROMS. I would appreciate comments on either topics. 